\title{
Assessing leadership and employee safety participation in managing health and safety: a case study of K-Refinery and Petrochemical Companies (K-RPC)
}

\author{
S. C. Theophilus \& J. H. Shaibu \\ Department of Geography, Environment and Disaster Management, \\ Coventry University, UK
}

\begin{abstract}
The ever increasing need for energy resources creates complex health and safety challenges in petroleum and petrochemical companies and human participation is crucial to the management of health and safety particularly in K-Refinery and Petrochemical companies (K-RPC). The research set out to differentiate management safety performance behaviour into two different types, assess the impact of employee and management safety participation on overall safety performance and to evaluate the impact of employees' safety knowledge/perception on compliant behaviour in K-RPC. Methods employed in the assessment are the Mann Whitney U Test, Correlation Analysis and descriptive statistics. The results suggested that there is no difference in mean ranking between management and employees regarding the level of management commitment, indicating a high level of participation. A significant negative correlation was found between employees' safety knowledge and safety compliant behaviour, which implies a low practical application of safety knowledge gained through training. Therefore, though management participation in safety issues in $\mathrm{K}-\mathrm{RPC}$ is perceived to be high, this commitment did not impact on the overall levels of safety performance in K-RPC. Hence, the manner in which participation in work-related safety is exhibited has an overwhelming impact on safety performance. When participation takes the form of directives rather than direct and true active involvement during work operations, the empowering safety
\end{abstract}


leadership which is a fundamental drive to the attainment of an incident-free work will be missing.

Keywords: health and safety, management participation, employee participation, management performance behaviours, management commitment, safety performance behaviours, safety participation, refinery and petrochemical company, occupational accident, safety outcomes, safety culture, safety climate.

\section{Introduction}

Global estimates of occupational accidents have revealed that 960,000 workers suffer from work related injuries, 5,330 die of work related disease and approximately 1,020 die of occupational accidents daily Hämäläinen et al. [1]. Though there are several factors leading to these figures, human and organisational factors have been identified in literature and accident investigations as key factors influencing the occurrence of accidents in the workplace Martínez-Córcoles et al. [2]. The major role of human and organisational related failure, such as technical failures, poor communication and ineffective permit to work system, is welldocumented in the case of Piper Alpha fire disaster of 6 July 1988 (Gordon et al. [3]).

\subsection{Employee safety compliance and safety participation}

There are two components of employee safety performance behaviours: safety compliance and safety participation Martínez-Córcoles et al. [2]. As explained by Martínez-Córcoles et al. [2] safety compliance deals with safety standards, safety procedures and safe system of work. This aspect of safety performance behaviours affects the work and the individuals directly. Thus by complying with company approved code of conduct the individuals helps to establish a safe workplace. On the other hand, safety participation requires workers to participate in activities such as safety meetings, voluntary safety tasks and trainings or even helping colleagues at work. This component of safety performance helps to develop a safe work environment. We note that whereas safety compliance deals with activities prescribed by formal job descriptions, safety participation deals with individuals voluntary actions that back the establishment of good safety culture and climate.

Gordon et al. [3] classified accident based on human error into two namely; skill-based (slip of action and lapse of memory) and mistakes (rule-based and knowledge based mistakes). Since organisations safety performance depends on workers and management skills, knowledge and compliance to rule, there is therefore the need to investigate management and employee safety participation in close juxtaposition with the entire structure of managing health and safety.

\subsection{Management safety compliance and safety participation}

The Health and Safety at work Act (1974) states that organisation must:

1. Provide a written safety health and safety policy (if they employ five or more people); 
2. Assess risk to employees, customers, partners and any other people who could be affected by their activities;

3. Arrange for the effective planning, organisation, control, monitoring and review of preventive and protective measures;

4. Ensure they have access to competent health and safety advise; and

5. Consult employee about their risk at work and current preventative protective measure.

Therefore, similar to employee safety performance behaviours described in section 1.1, we can divide management performance behaviours into two: management safety compliance and management safety participation as shown in figure 1. Under management safety compliance, organisations are expected to comply with the obligations imposed by the health and safety laws, for example, the Health and Safety at work Act (1974). This aspect of management safety performance behaviours obviously affects the work and the organisations directly and sanctions may include fines, imprisonment and disqualification and failures may have serious consequences for the organisation and individuals. On the other hand management safety participation covers activities such as safety leadership practices and style, management commitment to and involvement in safety, management attitude to safety, management commitment to production versus safety, decisiveness, resource allocation or even humanistic management practices.

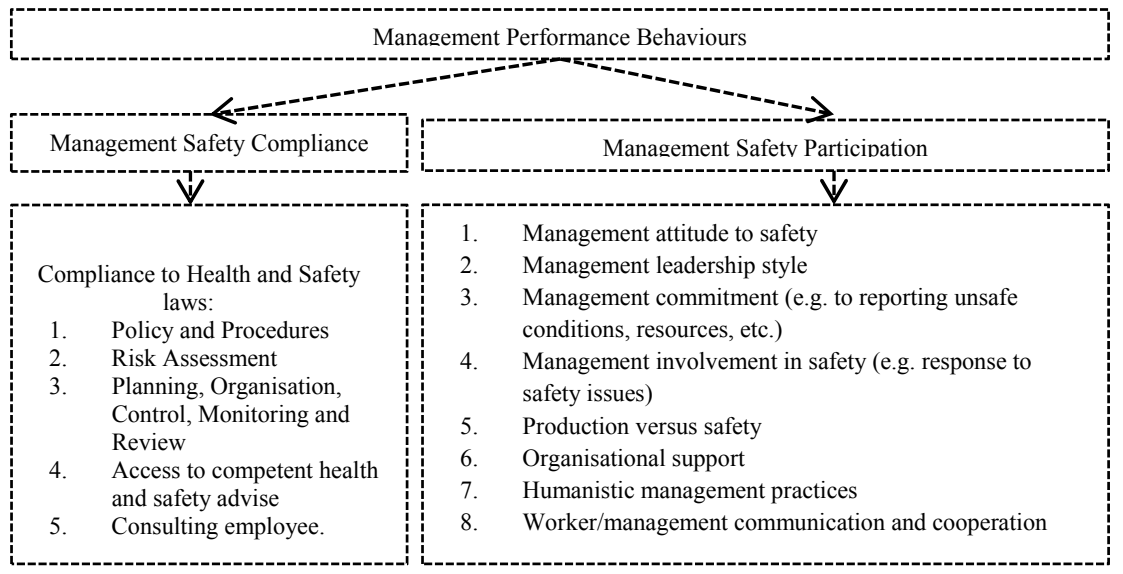

Figure 1: Two divisions of management performance behaviours.

Earlier research showed that leadership participation does influence employee safety behaviour [4-6]. HSE researches have also identified perception of management commitment to safety as a major factor influencing safety climate [7-9]. This present study aims to achieve three things. Firstly, management safety performance behaviour is differentiated into two different types (see figure 1) to aid assessment of safety culture in the petrochemical industry, secondly, this study will assess the impact of employee and management safety participation on safety performance. Emphasis will be placed on key aspects of safety participation 
highlighted in figure 1 including: management response to safety problems during work, provision of safety information, relation with workers regarding safe work, workers involvement in safety decisions, management commitment to reporting unsafe conditions, management preference of HSE to production targets, management response to safety issues. Finally, it will evaluate the impact of employees' safety knowledge/ perception on compliant behaviour in K-RPC.

\section{Research methodology}

The research sample was made up of 210 workers from K-Refinery and Petrochemical Company. All major responsibility levels and functionality of the refinery and petrochemical company made up of 397 employees were included. A representative rate of $70 \%$ was obtained. The questionnaire consisted of three parts. Part A asked question on personal attributes, awareness and contribution towards health and safety. Part B adopted the 5 questions of the Empowerment Leadership Questionnaire (ELQ) developed by Arnold et al. [10] to assess leadership behavioural impact on the cultural behaviour of employees in the organisation. ELQ was adopted because its validity and reliability had been verified by previous research on health and safety. The adopted questionnaire was further checked by a research team consisting of three HSE instructors, four National Oil Companies (NOCs) and four International Oil Companies (IOCs) HSE managers. In Part C two broad indicator used by Carol et al. [11] to measure safety performance: safety participation and safety compliance was adopted.

\subsection{Research hypothesis}

Both management and employees carried out ranking based on these criteria. The null and alternative hypotheses are stated as follows:

$\mathrm{H} 0$ : there is no difference in mean agreement between employees and management regarding management participation in safety.

H1: there is a difference in mean agreement between employees and management regarding management participation in safety.

Decision rule: reject the null hypothesis $(\mathrm{H} 0)$ if computed value $>$ critical value

Do not reject the null hypothesis $(\mathrm{H} 0)$ if computed value $<$ critical value

\subsection{Wilcoxon Rank-Sum Tests}

The Wilcoxon Rank-Sum Test was conducted using SPSS with the level of management safety participation being the test variable whiles the grouping variable is represented by the category of the respondent (employee or management). The p-value was compared with 0.05 (5\% level significance level) and conclusions drawn based on the results. With regards to management safety participation, three factors of management safety participation variables were employed in conducting the Wilcoxon Sum Rank test (Mann Whitney U test for independent samples). Management response to health and safety issues, management preference of HSE to production targets and management commitment to reporting unsafe conditions were used as proxies to measure the 
extent of management safety participation. Each of the indicators was ranked between 1 and 5 with 1 representing strong non-management participation and 5 representing strong management participation. The use of the Wilcoxon RankSum test is justified by the nature of the study where ordinal data was generated from two independent samples (employees and management) making the use of non-parametric statistics most appropriate. According to Gwet [12], the Wilcoxon Rank-Sum Test is validated by conditions such as the raw data being ordinal prior to transformation, independent samples and the selection being random.

\subsection{Correlation analysis}

Correlation analysis was used to establish whether there is any linear association between employee and management participation and the level of safety performance, and whether any relationship exists between employees' knowledge/perception of safety and their level of safety compliant behaviour. Values were coded and the analyses conducted in SPSS to generate the correlation coefficient. The Spearman's rank correlation coefficient was used for the test. Values normally range between +1 and -1 with +1 being a perfectly positive correlation and -1 indicating perfectly negative correlation.

\section{Results and discussion}

The empirical data analysis took the case study approach to unveil the reality of health and safety issues within the management and operational environment of K-RPC. The results of each objective are presented and discussed in relation to other empirical studies conducted on the topic of safety management.

\subsection{Mann-Whitney Test}

Table 1 shows Mann-Whitney Test mean rank and the sum of ranks for the two groups of participants in the safety of K-RPC (employees and management).

Table 1: Results of Mann-Whitney Test.

\begin{tabular}{l|l|l|l|l|}
\hline \multirow{2}{*}{$\begin{array}{l}\text { Management Safety } \\
\text { Participation Indices }\end{array}$} & \multicolumn{4}{|c}{ Ranking } \\
\cline { 2 - 6 } & $\begin{array}{l}\text { Position in } \\
\text { organisation }\end{array}$ & $\begin{array}{l}\text { No. of } \\
\text { Respondents }\end{array}$ & $\begin{array}{l}\text { Mean } \\
\text { Rank }\end{array}$ & $\begin{array}{l}\text { Sum of } \\
\text { Ranks }\end{array}$ \\
\hline \multirow{2}{*}{$\begin{array}{l}\text { Management response to } \\
\text { health and safety issues }\end{array}$} & Management & 67 & 121.25 & 8123.50 \\
\cline { 2 - 6 } & Employee & 143 & 98.12 & 14031.50 \\
\cline { 2 - 6 } & Total & 210 & & \\
\hline \multirow{2}{*}{$\begin{array}{l}\text { Management preference } \\
\text { of HSE to production } \\
\text { targets }\end{array}$} & Management & 67 & 114.72 & 7686.50 \\
\cline { 2 - 6 } & Employee & 143 & 101.18 & 14468.50 \\
\cline { 2 - 6 } & Total & $\mathbf{2 1 0}$ & & \\
\hline \multirow{2}{*}{$\begin{array}{l}\text { Management } \\
\text { commitment to reporting } \\
\text { unsafe conditions }\end{array}$} & Management & 67 & 112.41 & 7531.50 \\
\cline { 2 - 6 } & Employee & 143 & 102.26 & 14623.50 \\
\cline { 2 - 6 } & Total & $\mathbf{2 1 0}$ & & \\
\hline
\end{tabular}


In all three indicators of employees and management safety participation, the mean ranks of 67 staff in management and supervisory positions were higher at $121.25,114.72$ and 112.41 for management response to health and safety issues, management preference of HSE to production targets and management commitment to reporting unsafe conditions respectively. This implies that senior managers and supervisors generally regard management as having a greater participation in health and safety issues than lower level employees. The reasons and implications of these results are discussed subsequently.

A test of the significance of the results from the Mann-Whitney $U$ test is presented in Table 2. The null hypothesis that was formulated for the test states that there is no difference in mean agreement between employees and management regarding the indicators of management participation in safety. The p-value of the 2-tailed test of management response to safety issues (0.004) is less than 0.05 . Therefore, at the $90 \%$ confidence level, the null hypothesis is rejected and the conclusion drawn that there is a difference in mean ranks between management and employees regarding participation in safety issues by management. In respect of management preference of HSE over production targets, the p-value of the test (0.118) is greater than 0.05 hence the null hypothesis is not rejected and the conclusion is that there is no significant difference in mean ranks between management and employees regarding management preference of HSE over production targets. Similarly, the null hypothesis is not rejected in the case of the test of management commitment to reporting unsafe conditions. The conclusion is that no significant difference exists between management and employees ranking of management commitment to reporting unsafe conditions in K-RPC. Generally, it can be concluded that there is a high management participation in safety issues in K-RPC as evidenced by the statistical test and high mean rank scores.

Table 2: Significance Test Statistics of the mean agreement between employees and management regarding management participation.

\begin{tabular}{l|l|l|l}
\hline Test Statistics & $\begin{array}{l}\text { Management response } \\
\text { to health and safety } \\
\text { issues }\end{array}$ & $\begin{array}{l}\text { Management } \\
\text { preference of } \\
\text { HSE to } \\
\text { production } \\
\text { targets }\end{array}$ & $\begin{array}{l}\text { Management } \\
\text { commitment to } \\
\text { reporting unsafe } \\
\text { conditions }\end{array}$ \\
\hline $\begin{array}{l}\text { Mann-Whitney } \\
\text { U }\end{array}$ & 3735.500 & 4172.500 & 4327.500 \\
\hline Wilcoxon W & 14031.500 & 14468.500 & 14623.500 \\
\hline Z-Test & -2.854 & -1.562 & -1.279 \\
\hline
\end{tabular}

This finding can be attributed to the greater interaction and involvement of senior staff and supervisors in decision making in comparison with employees. This finding can be attributed to the greater interaction and involvement of senior staff and supervisors in decision making in comparison with employees. As these managers are responsible for ensuring that tasks are performed safely, they usually 
share in the blame if safety is compromised and would want to be seen as carrying out their duties diligently. This accounts for the high ranking of management participation by supervisors and senior staff. On the other hand, employees are generally involved directly in the job and are more abreast with the practical realities of safety. They are also most affected if management is less committed to safety and are more likely to rank management participation low if their expectations regarding safety are not met. In the survey conducted, lower level employees also constitute the majority (143) of the respondents and their views can be regarded as more representative of the study population. The views of employees are therefore more reflective of reality than that of higher level employees. However, the results of the Mann-Whitney test suggest that the difference in mean ranking by management and employees is not statistically significant, a finding which is supported by evidence from descriptive statistics. It can therefore be concluded that management of the K-RPC participate in health and safety issues.

Frequency of occurrence of work-related health problems was used to assess the overall impact of the perceived management participation in safety. Results in figure 2 show that the overall safety performance is as low as $78 \%$. Respondents (senior staff and lower level employees) agreed to varying degrees that workrelated accidents and illnesses were rampant and easily developed. This finding is inconsistent with most literature on safety leadership.

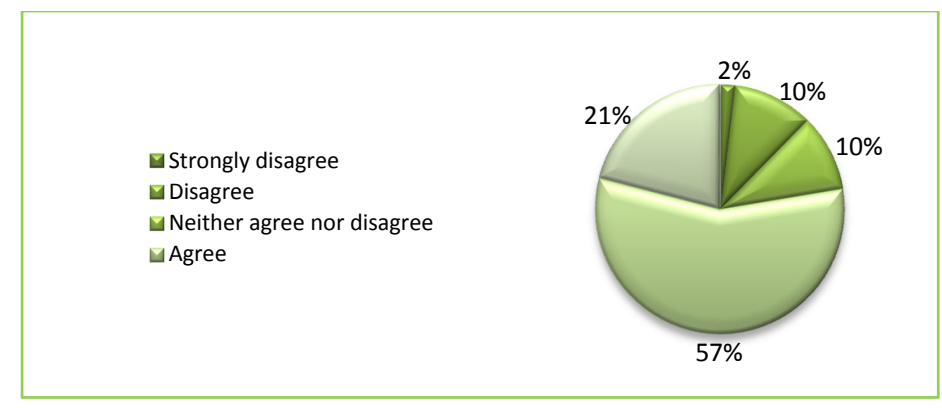

Figure 2: $\quad$ Frequency of occurrence of work-related health problems.

Roger et al. [13] noted contrary to this finding that perceived management commitment results in true implementation of safety measures that result in high levels of safety performance. This result implies that the manner in which participation in work-related safety is exhibited has an overwhelming impact on safety performance. In K-RPC, participation takes the form of directives rather than direct active involvement during work operations. This makes the discovery by Knode and Wham [14] that leading by example through active involvement underpins the significance of safety leadership as a fundamental drive to the attainment of an incident-free work. It is therefore crucial to redefine management performance behaviours in safety as not only involving the dissemination of health and safety laws and directives to subordinates on the performance of task but active involvement of senior level staff. This can be carried out through regular 
visits and walk-around during work, emphasising safety over production targets, and active involvement during safety training of employees, provision of the right tools, machinery and safety equipment and emphasis on the correct use of such materials.

\subsection{The extent of management participation in ensuring health and safety during operations}

To assess the extent of management participation, four basic indicators were designed as measures of the extent to which management ensures safety during work operations. The indicators include management response to safety problems during work, relations with workers regarding safe work, dissemination of safety information and involvement in safety decisions. Respondents agreed to varying degrees with these indicators of the extent to which management are involved in ensuring safety during work activities. The percentages of respondents who rated each indicator of management commitment to safety participation are shown in figure 3 .

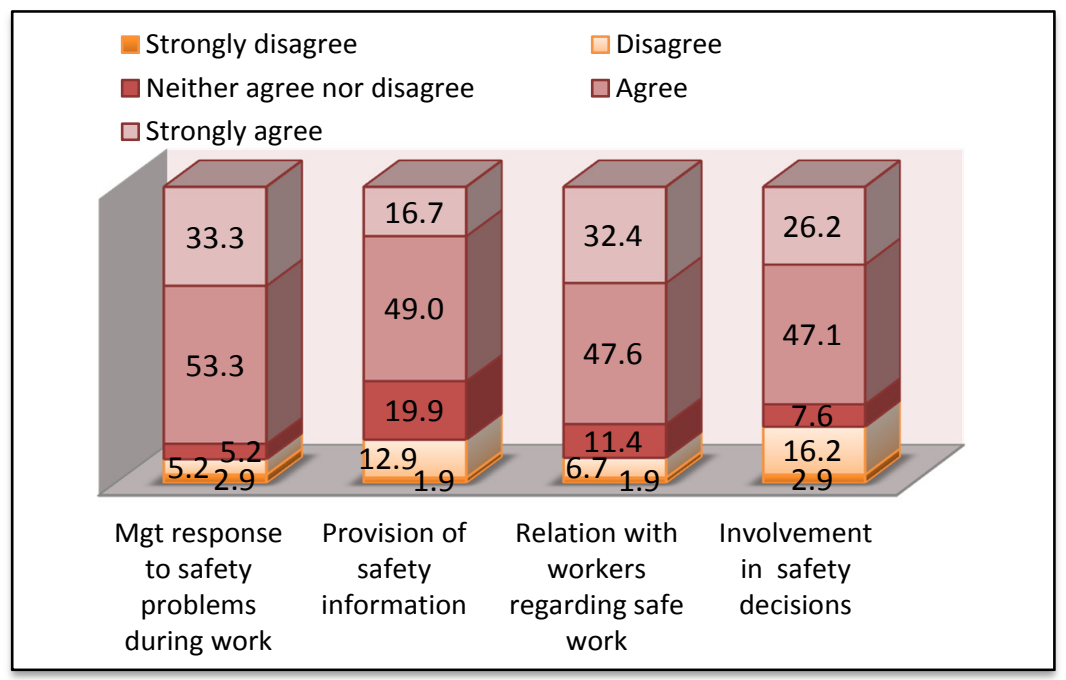

Figure 3: The extent of management participation during work using four indicators.

As depicted in figure 3, a greater percentage of respondents ranging from $47 \%$ to $53 \%$ agreed that management respond to safety problems during work, line managers provide the required information on safety during work operations, managers relate well with workers regarding safety issues and that management are actively involved in decisions that affect workers safety during work. A significant number of participants strongly agreed that management participate in various ways during work operations at K-RPC whereas less than $20 \%$ of participants either disagreed or strongly disagreed with any form of management involvement during work. 


\subsection{The relationship between employees' knowledge/ perception and safety compliant behaviour}

The correlation analysis performed to test whether any relationship exist between employees knowledge/perception of safety and their level of safety compliant behaviour as indicated by the practical application of safety rules and compliance with safety practices revealed rather unexpected results. Employees' Knowledge/perception was measured by their awareness of the safety regulations applicable in their work environments such as control of substances hazardous to health, electricity, display screen equipment, manual handling and personal protective equipment regulations.

A second measure of employee perception was their knowledge and views on why they regard knowledge of safety issues as important to the organisation. Major reasons given for why knowledge of safety is important include accident prevention $(46 \%)$, improved quality performance $(24 \%)$ and higher productivity (11\%). Regarding awareness of HSE regulations, 34\% of respondents were aware of control of hazardous substances regulations, 22\% had knowledge of PPE regulation, $7 \%$ were aware of electricity at work regulations whiles $5 \%$ knew of manual handling regulations. Given that these regulations do not necessarily apply to all employees concomitantly, it can be concluded that employees have a high knowledge of health and safety within the organisation. The Spearman's rank correlation and the significance of the coefficients between the three variables of compliance and knowledge of health and safety are shown in Table 3.

Table 3: Correlation Analysis between employee knowledge/perception and safety compliance variables.

\section{Correlations}

\begin{tabular}{|c|c|c|c|c|c|}
\hline \multirow{10}{*}{ 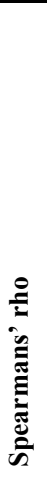 } & & & $\begin{array}{c}\text { Perception/ } \\
\text { Knowledge } \\
\text { on HSE }\end{array}$ & $\begin{array}{c}\text { Practical } \\
\text { application } \\
\text { of safety } \\
\text { rules }\end{array}$ & $\begin{array}{c}\text { Compliance } \\
\text { with safety } \\
\text { practices } \\
\text { during work }\end{array}$ \\
\hline & \multirow{3}{*}{$\begin{array}{l}\text { Perception/ } \\
\text { Knowledge on } \\
\text { HSE }\end{array}$} & Correlation Coefficient & 1.000 & $-0.189^{* *}$ & $-0.150^{*}$ \\
\hline & & Sig. (2-tailed) & - & 0.006 & 0.030 \\
\hline & & $\mathrm{N}$ & 210 & 210 & 210 \\
\hline & \multirow{3}{*}{$\begin{array}{l}\text { Practical } \\
\text { application of } \\
\text { safety rules }\end{array}$} & Correlation Coefficient & $-0.189^{* *}$ & 1.000 & $0.137^{*}$ \\
\hline & & Sig. (2-tailed) & 0.006 & . & 0.048 \\
\hline & & $\mathrm{N}$ & 210 & 210 & 210 \\
\hline & \multirow{3}{*}{$\begin{array}{l}\text { Compliance } \\
\text { with safety } \\
\text { practices } \\
\text { during work }\end{array}$} & Correlation Coefficient & $-0.150^{*}$ & $0.137^{*}$ & 1.000 \\
\hline & & Sig. (2-tailed) & 0.030 & 0.048 & 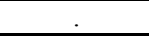 \\
\hline & & $\mathrm{N}$ & 210 & 210 & 210 \\
\hline \multicolumn{6}{|c|}{$* *$. Correlation is significant at the 0.01 level (2-tailed) } \\
\hline
\end{tabular}

From Table 3, there exists a negative correlation between perception/ knowledge of HSE and the practical application of safety rules at work as evidenced by a negative correlation coefficient (-0.189). In a similar vein, a coefficient of -0.150 shows that a negative relationship exists between employees' knowledge/perception and compliance with safety practices during work. Using 
these two indicators of safety compliance, there is sufficient evidence to confirm a negative association between employees' knowledge/perception of safety and safety compliant behaviour among employees of K-RPC.

The negative relationship among these safety variables implies that employees of the K-PRC in carrying out their daily tasks do not sufficiently apply their knowledge and positive perception of safety. The result of this study is contrary to that of Martínez-Córcoles et al. [2] in which a significantly positive relationship was found between safety climate (employees' knowledge) and safety behaviours. Several reasons may have accounted for the rather unusual relationship revealed in the analysis. First, safety rules are regarded as procedural and their application is seen as a hindrance to speedy work. Also, the nature of safety training provided may be another contributory factor to non-compliance with the requisite safety behaviours; if emphasis is placed on the need to impact knowledge during training programmes organised rather than the need to act safely. The results of the study therefore make a significant revelation that the application of knowledge on safety is equally influenced by a practical demonstration of the need for safe procedures.

So many constraint exits in this study, first we used self-report from K-RPC staff to measure safety performance, so responders' tendencies to respond in a consistent and socially desirable manner my lead to inflated result. Hence we measure perceived safety performance as the real safety performance is not known. We have used just three items from the management and employee safety participation. Finally we have not taken mediator variables into account.

\section{Conclusion}

Though management participation in safety issues in K-RPC is perceived to be high, this commitment did not impact on the overall levels of safety performance in K-RPC. Hence we conclude that the manner in which participation in work-related safety is exhibited has an overwhelming impact on safety performance. We also conclude that when participation takes the form of directives rather than direct and true active involvement during work operations, the safety leadership which is a fundamental drive to the attainment of an incidentfree work will be missing. The implication would be that employees in carrying out their daily tasks would not be keen in applying their knowledge and this would show in the overall negative safety performance.

\section{Acknowledgement}

The authors' special appreciation goes to the entire staff of K-Refinery and Petrochemical Company for their active participation and valuable opinions provided through the questionnaires.

\section{References}

[1] Hämäläinen, P., Leena Saarela, K. \& Takala, J., Global Trend According to Estimated Number of Occupational Accidents and Fatal Work-Related Diseases at Region and Country Level, Journal of Safety Research, 40(2), pp. 125-139, 2009. 
[2] Martínez-Córcoles, M., Gracia, F., Tomás, I. \& Peiró, J. M., Leadership and Employees' Perceived Safety Behaviours in a Nuclear Power Plant: A Structural Equation Model, Safety Science, 49(8-9), pp. 1118-1129, 2011.

[3] Gordon, R., Flin, R., Mearns, K. \& Fleming, M., Assessing the Human Factors Causes of Accidents in the Offshore Oil Industry: SPE Health, proc. 9th SPE Conf. on Safety \& Environment in Oil and Gas Exploration and Production, New Orleans, Louisiana, pp. 9-12, 1996.

[4] Barling, J., Loughlin, C. \& Kelloway, E., Development and test of a model linking safety-specific transformational leadership and occupational safety. Journal of Applied Psychology, 87, pp. 488-496, 2002.

[5] Hofmann, D.A. \& Morgeson, F.P., Safety-related behaviour as a social exchange. Journal of Applied Psychology 84, pp. 286-296, 1999.

[6] Komaki, J., Collins, R. \& Penn, P., The role of performance antecedents and consequences in work motivation. Journal of Applied Psychology, 67, pp. 334-340, 1982.

[7] Dedobbeleer, N. \& Béland, F., Safety climate in construction sites, Journal of Occupational Accidents, 12(1-3), pp. 99-100, 1990.

[8] Díaz, R, I. \& Cabrera, D. D., Safety climate and attitude as evaluation measures of organizational safety, Accident Analysis \& Prevention, 29(5), pp. 643-650, 1997.

[9] Dov Zohar, D. \& Luria, G., The use of supervisory practices as leverage to improve safety behavior: A cross-level intervention model, Journal of Safety Research, 34(5), pp. 567-577, 2003.

[10] Arnold, J., Arad, S., Rhoades, J. \& Drasgow, F., The empowering leadership questionnaire: the construction and validation of a new scale for measuring leader behaviours, Journal of organizational behaviours, 21, pp. 249-269, 2000.

[11] Carol K. H. H., Albert P.C. C., Michael C.H. Y., Relationships between safety climate and safety performance of building repair, maintenance, minor alteration, and addition (RMAA) works, Safety Science, 65, pp. 10-19, 2014.

[12] Gwet, L., The Practical Guide to Statistics, Advanced Analytics Press, USA, p. 23, 2011.

[13] Roger, I. Flin, R. Mearns, K. \& Hetherington, C., Development of a Safety Leadership Tool for Senior Managers, proc. 12th SPE International Conf. on Health, Safety and Environment in Oil and Gas Exploration and Production, Rio de Janeiro, Brazil, 2010.

[14] Knode, T. \& Wham, T., Safety Leadership: Lessons Learned from Developing and Delivering Content on Building the Safety Capacity of an Organization, proc. 11th International Conf. on Health, Safety and Environment in Oil and Gas Exploration and Production, Perth Australia, 2012. 